Гребенщиков Иван Валерьевич

аспирант кафедры социологии политических и социальных процессов

Санкт-Петербургского государственного университета

\section{ГОСУДАРСТВО И ЮРИДИЧЕСКОЕ ПОЛЕ В ДИСКУРСЕ ОБ ЭКСТРЕМИЗМЕ}

\section{Аннотация:}

В статье анализируется влияние государства на звучание юридического дискурса об экстремизме. Рассмотрено пространство важных черт нормативного текста и осуществлено их соотнесение со значимыми характеристиками их производителей. Определены параметры бюрократического влияния на профильное звучание юридического концепта "экстремизм». Для осмысления и выявления государственного участия в целевом дискурсе, а также установления аутентичных смыслов его звучания используются теоретические конструкты анализа П. Бурдье. Изучены место и роль юридического поля как агента государства в процессе формирования нормативного прочтения экстремизма. Предложены функции и эффректы идентифицированных смыслов: обеспечение безопасности, универсальность, монополизация публичного и символического, защита отправления и воспроизводства власти бюрократического поля. Аналитическая призма исследования позволяет по-новому посмотреть на означаемое знака «экстремизм».

Ключевые слова:

экстремизм, дискурс, государство, бюрократическое поле, юридическое поле, капитал, публичное, власть.

\section{Grebenshchikov Ivan Valeryevich}

PhD student, Sociology of Political and Social Processes Department St. Petersburg State University

\section{GOVERNMENT AND JURIDICAL FIELD IN THE DISCOURSE ON EXTREMISM}

Summary

The study analyzes the impact of the government on the sound-image of the legal discourse on extremism. The paper reviews the important features of the regulatory text and their correlation with the significant characteristics of their producers. The research identifies the bureaucratic influence on the field-oriented legal concept of extremism. The theoretical constructs of $P$. Bourdieu's analysis are used to comprehend and reveal government participation in the target discourse as well as to determine its authentic meaning. The paper examines the place and role of the juridical field as an agent of the state in the process of regulatory interpretation of extremism. The author reviews functions and effects of identified meaning: safety, universality, monopolization of public and symbolic components, protection of exercise of power in the bureaucratic field. The analytical study allows one to rethink the signified of such sign as extremism.

Keywords: extremism, discourse, government, bureaucratic field juridical field, capital, public, power.

Ответ на вопрос идентификации экстремизма как знака системы профильных значений детерминируется влиянием ряда агентов социального пространства, отвечающих за конвенциональное понимание данного означающего. На сегодняшний день можно говорить о формировании устойчивого и рутинизированного теоретико-практического универсума вокруг концепта «экстремизм». Рассматривая данный универсум, можно диагностировать определенное пространство с конкретной структурой, обусловленное как влиянием значимых участников обсуждения экстремизма, так и существенными свойствами подобного обсуждения. Другими словами, целевой универсум находится в зависимости от тех, кто говорит в профильном дискурсе.

Очевидно, что один из самых весомых вкладов в развитие дискурса об экстремизме внесло научное поле. В частности, проблематика экстремизма раскрывается в работах Е.В. Сальникова, Э.В. Улезко, С.А. Сергеева, С.Н. Фридинского, А.А. Козлова, Е.О. Кубякина, В.В. Устинова, Р. Тамаева и других исследователей. Еще одним важным агентом производства профильного дискурса является государство в лице дифференцированной структуры агентов бюрократического поля. Также в закреплении актуального качества «универсума экстремизма» участвует поле СМИ.

Данное пространство субъектов-участников представляет собой, во-первых, иерархию внутренних диспозиций, во-вторых, монополию на производство и регуляцию профильного дискурса. Таким образом, определение своеобразия структурных и содержательных позиций субъектов пространства дискурса об экстремизме является проблемой комплексного исследования. В рамках данной статьи мы ограничимся рассмотрением места и роли юридического поля как агента государства в процессе формирования современного отечественного звучания понятия «экстремизм».

Предметом рассмотрения в работе выступает юридическое понятие экстремизма в системе многоаспектности его значений и символизма. Целью предпринятого изучения предмета является установление места и роли государства в конструировании категории экстремизма как объекта дискурса. Задачи анализа заключаются в диссекции юридического звучания экстре- 
мизма; определении его функций и эффектов; идентификации места, роли и субъектности государства в циркуляции профильного дискурса. Таким образом, организовано исследование диспозиции одного из агентов бюрократического поля (юридического), участвующего в дискурсе об экстремизме, проанализированы форма, содержание и функция профильного высказывания.

Ключевой методологической предпосылкой предпринятой оценки выступает программа исследования проявлений социального пространства, позволяющая взглянуть на экстремизм, с одной стороны, в системе монополии влияния государства, а с другой - в призме воздействия его отдельных структурных элементов или полей, образующих актуальное метаполе дискурса об экстремизме. Подобного рода программа в развернутом виде представлена в курсе лекций П. Бурдье «О государстве», прочитанном в Коллеж де Франс в 1989-1992 гг. [1]. Анализ призван «выстроить актуальные эмпирические предметы так, чтобы попытаться найти государство под аналитическим скальпелем, т. е. выстроить исторически наблюдаемые предметы таким образом, чтобы в частном случае можно было найти всеобщие механизмы, к которым привязан термин "государство"» [2].

В настоящей работе используются понятия поля и разных видов капитала. В рамках исследования особую актуальность имеет категория символического капитала, поскольку этот концепт является основой государственного господства: «та фрорма капитала, которая рождается из таких отношений между тем или иным видом капитала и социализированными агентами, в силу которых этот вид капитала познается и признается» [3]. Другим важным инструментом анализа выступает понятие поля. Согласно позиции П. Бурдье, поле - специфическая среда, где осуществляются социальные отношения и взаимодействия между различными позициями. Другими словами, дефиниция поля представляет собой такое структурированное пространство позиций, внутри которого существуют иерархия и доминирование позиций [4].

Важным вспомогательным элементом, обеспечивающим наглядность субъектно-объектных отношений, рассматриваемых в ходе анализа, выступает понятие дискурса. В данной работе оно используется в рамках теории дискурса М. Фуко, согласно которой дискурсом является совокупность речевых актов, объединенных одной проблематизацией [5, с. 133]. Уточняя определение проблематизации, М. Фуко говорит о том, что «это совокупность дискурсивных и недискурсивных практик, вводящих нечто в игру истинного или ложного и конституирующих эту игру в качестве объекта мысли» [6, с. 80]. Необходимо также отметить, что у П. Бурдье понятие дискурса тесно связано с категорией поля или логики поля: «дискурс - это те позиции, которые возможны в соответствующем поле, и те речи, которые возможно держать с этих позиций, т. е. дискурс можно представить как совокупность позиций и диспозиций поля, образованного дискурсом» [7, с. 137]. Подобного рода компромисс позволяет исследовать ограниченную целевую дискурсивную формацию, совмещая в качестве аналитического инструмента концепт дискурса М. Фуко и теоретический конструкт поля П. Бурдье.

Итак, на начальном этапе, используя методологический подход П. Бурдье, необходимо сконцентрировать внимание на бюрократическом поле или пространстве агентов и институтов, располагающих метавластью над всеми остальными полями. Далее, согласно П. Бурдье, для целевой организации агентов бюрократического поля нужно определить совокупности значимых агентов и свойств профильного дискурса. В первом случае критерием является отбор агентов, способных участвовать в дискурсе об экстремизме. Во втором речь идет о значимых качествах производимого профильного дискурса, благодаря которым оказывают воздействие.

Наиболее значимым агентом бюрократического поля по конституированию понятия «экстремизм» выступает юридическое поле. Его важность в процессе дискурса об экстремизме не вызывает сомнения, поскольку именно оно фрормулирует нормативное звучание категории «экстремизм». Кроме того, существенные свойства профильного дискурса нашли выражение в тексте федерального закона «О противодействии экстремистской деятельности» [8].

Напомним, что согласно подходу П. Бурдье юридическое поле заинтересовано в создании легитимирующей теории государства. На примере рассматриваемого документа мы видим то, что называется fictio juris, или юридическую фрабрикацию, частичное изобретение дискурса по легитимации государства. Другими словами, юридическое поле инвестирует свой «капитал слов» в государство, которое в свою очередь приводит новообретенную истину в исполнение в целях конструирования определенной реальности [9, с. 601]. Таким образом, общий процедурный принцип в отношении анализируемого документа заключается в соотнесении структуры пространства текста со структурой пространства его производителей для определения, почему эти тексты такие, а не другие [10, с. 493].

Применяя данную аналитическую матрицу П. Бурдье, рассмотрим некоторые сегменты текста концептуально важной части закона «О противодействии экстремистской деятельности», где устанавливается понятийный узус государственного толкования экстремизма (ст. 1. «Основные понятия»). Конструкторы изначально подчеркивают деятельностный аспект понятия - посредством тождества экстремизма и экстремистской деятельности. Данная специфика объясняется 
тем, что государство выступает монополией на все виды капитала, особенно капитала на безопасность. Как утверждал Б. Спиноза, «добродетель государства - безопасность» [11, с. 289]. Поэтому определение, негативное в отношении безопасности, фрормулируется через действие по отрицанию безопасности.

«Насильственное изменение основ конституционного строя и нарушение целостности Российской Федерации». В данном случае наблюдается отсылка к другому «изобретению» юридического поля - тексту Конституции. Такого рода прием является типичным не только для юридического производства, но и для государства в целом - осуществляется предоставление гарантии, warrant достоверности смысла фрормулировки [12, с. 550]. Происходит делегирование авторитета документа, ставшего частью «нормативной реальности» (Конституции), в качестве подтверждения легитимности вводимого «нормативного неологизма» «экстремизм».

«Возбуждение социальной, расовой, национальной или религиозной розни». Данная формулировка закона является следствием определения государства М. Вебером, который называет его монополией на легитимное насилие. П. Бурдье дополняет данную формулировку, говоря, что государство есть монополия на легитимное фризическое и символическое насилие [13, с. 50]. Речь идет о том, что субъектность любой розни в государстве может принадлежать только государству. Если посмотреть на значение слова «рознь», то оно определяется как вражда, несогласие, ссора. Поскольку государство стремится удержать монопольное влияние на формирование образа врага, его кодификацию, то любое внешнее действие в этом отношении недопустимо. Представленные предпосылки розни - раса, национальность, религия - структурные элементы общего символического капитала, имеющегося в распоряжении государства. Он может быть использован только в интересах последнего, поэтому любые сторонние заимствования этого ресурса определяются как противозаконные.

«Пропаганда исключительности, превосходства либо неполноценности человека по признаку его социальной, расовой, национальной, религиозной или языковой принадлежности или отношения к религии». Помимо того что любой публичный политический или политизированный дискурс (пропаганда в данном случае) является монопольным правом государства, здесь следует отметить, что государство стремится к универсальному. Государство есть предпосылка, интегратор и структура универсального, которое капитализирует влияние всех пространств социальной жизни - от национальных измерений населения до их религиозных ориентаций. Получение бенефиций символического и экономического капитала со всего спектра дифференцированной социальной структуры, а не с его частностей - ключевая характеристика государства. Поэтому любая попытка дезинтеграции структуры, автономизация какого-либо поля определяются как преступление. Именно в спектре данного видения становится очевидной генеалогия представленных фрормулировок, создаваемых профессионалами универсального (юридическим полем), виртуозами универсализации частного интереса государственной знати [14, с. 662].

«Нарушение прав, свобод и законных интересов человека и гражданина в зависимости om его социальной, расовой, национальной, религиозной или языковой принадлежности или отношения к религии». Одной из наиболее общих функций государства являются производство и канонизация социальных классификаций [15, с. 62]. Поэтому любая попытка перераспределить монополию на отправление данной функции, тем более в нарушение правового дискурса, порицается государством. Важно понимать, что монополия государства на квантификацию и кодификацию людей не может быть оспорена, точнее, такая возможность должна быть заблокирована правовым дискурсом. Интегрируя в себя дифференцированных (по указанной принадлежности) граждан, государство придает им общую государственную идентичность (россияне), которая автоматически монополизируется субъектом-интегратором.

«Воспрепятствование осуществлению гражданами их избирательных прав и права на участие в рефререндуме или нарушение тайны голосования, соединенные с насилием либо угрозой его применения». Государство располагает монополией на свое воспроизводство. Выборы, референдумы - инструменты воспроизводства и стабильности власти. Любая попытка дестабилизировать, разрушить процесс воспроизводства определяется как негативная и преступная. Поэтому кодификация государства через понятие «граждане» представляется лишь фригурой речи, поскольку только государство устанавливает, кто является гражданином, а кто нет, у кого есть права, а кто их лишен. Таким образом, используемый конструкт «граждане» выступает латентным выражением категории «государство». Гражданин, особенно в процессе голосования, проявляет легитимную социальную идентичность, доверенную ему государственным фидуциаром [16].

«Воспрепятствование законной деятельности государственных органов, органов местного самоуправления, избирательных комиссий, общественных и религиозных объединений или иных организаций, соединенное с насилием либо угрозой его применения». Во-первых, в данной фрормулировке снова присутствует отсылка к системе легитимного права как подтверждение легитимности деятельности государственных органов и институтов. Во-вторых, необходимо обратить 
внимание на представленные элементы извлечения государственного метакапитала - государственные органы, органы местного самоуправления, избирательные комиссии и пр. Во многом речь идет о бюрократическом поле, которое связано «органической солидарностью, подразумеваемой разделением труда господства» [17, с. 678]. Именно консолидированный бюджет усилий данных структурных элементов бюрократического поля и представляет собой бюрократическую власть над всеми остальными полями. Поэтому любая угроза стабильности отправления функций любого из игроков бюрократического поля ставит под угрозу само существование государства.

«Пропаганда и публичное демонстрирование нацистской атрибутики или символики либо атрибутики или символики, сходных с нацистской атрибутикой или символикой до степени смешения, либо публичное демонстрирование атрибутики или символики экстремистских организаций». Данная фрормулировка носит признаки ортодоксального характера, поскольку есть (пусть осуждаемый) субъект сравнения - символико-семантическая, идеологическая парадигма национал-социализма. В этом, наверное, кроется слабое место позиционирования государства в данном контексте, поскольку «ортодоксия появляется в тот момент, когда уже есть гетеро» [18, с. 335]. Другим важным моментом выступают устойчивые связи, которые устанавливает нормативная трактовка экстремизма в российском законодательстве с совокупностью характеристик, так или иначе присущих национал-социалистической и в меньшей степени фрашистской идеологической парадигме. Можно сказать, что нормативная трактовка генерирует превалирующую суть экстремизма через образ расизма, национализма, фашизма.

Образование подобного уклона юридического дискурса прояснится, если обратить внимание на формирование нормативного акта как продукта достижения монополии на власть и определение нормы. П. Бурдье указывает, что изначально поле власти есть отдельное пространство, «внутри которого разные обладатели власти борются друг с другом за то, чтобы их власть была легитимной. Одна из ставок борьбы внутри поля власти - это власть над государством как метавласть, способная действовать на разные поля» [19, с. 566]. При этом следует понимать, что метавласть, чьим продуктом является рассматриваемый текст, одержала победу в борьбе за легитимность с другими полями власти. Устранение конкурентов - ключ к осуществлению метавласти. Данные предпосылки способны пролить свет на специфику происхождения устойчивых корреляций экстремизма с идеологическими конструктами национал-социализма в изучаемом тексте - речь идет о превенции посягательств потенциально конкурентного поля власти (националсоциализма, фашизма) на осуществление метавласти актуальной государственной знатью. Степень потенциальной претенциозности национал-социализма на роль метаполя власти представлена в работе Дж. Мосса «Кризис немецкой идеологии», где национал-социализм называется «литургией гражданской религии» [20, р. 60]. Именно поэтому любое актуальное метаполе государственной власти стремится обезопасить себя от конкуренции со столь сильным игроком, тем более что его могущество представлено историческим фактом господства.

Наконец, в этой части интересно рассмотреть понятия атрибутики и символики. Необходимо разобраться, почему именно данные конструкты указываются в системе трактовки экстремизма. В этом случае, безусловно, речь идет о сохранении монополии государства на производство, ввод в обращение, изъятие и коррекцию элементов символического капитала. Символика и атрибутика очевидным образом относятся к пространству символического капитала, который, согласно П. Бурдье, едва ли не более важен, чем капитал физический. Поэтому один из ключевых рисков актуальной государственной метавласти исходит из сегмента символического конкурентных властных полей. Поэтому парализовать, дискредитировать, изъять этот вид капитала из пространства публичного дискурса - примордиальная задача юридического поля.

«Публичные призывы к осуществлению указанных деяний либо массовое распространение заведомо экстремистских материалов, а равно их изготовление или хранение в целях массового распространения». Рассматривая данную формулировку, стоит исходить из понимания монополии государства на информационный капитал. Процесс накопления информационного капитала государства строго регламентирован. Процесс концентрации информации - это работа над ее унификацией для кодификации генеральных идей. Безусловно, представленное определение выстраивает фильтры для влияния сторонних идей, несущих риски снижения или девальвации общего, унифицированного информационного капитала государства. Другим важным моментом является делигитимация частного, претендующего на публичное. Следовательно, пространство официального производит цензуру в публичном поле на предмет установления таких «заведомо экстремистских материалов», которые не могут быть представлены в системе общедоступного дискурса, поскольку не согласуются с дискурсом, «который должен быть единодушно признан в качестве единодушного выражения единодушной группы» [21, с. 123].

Таким образом, применение аналитического подхода П. Бурдье к пространству текста, производимому юридическим полем, позволяет по-новому взглянуть на рутинизированные нормативные знаки. Соотнесение пространства проанализированного текста с характерными чертами его производителя (юридического поля как агента государства) дает возможность проявить смыслы, 
цели и позиции, которые принадлежат государству в дискурсе об экстремизме. Стремление к монополизации публичного, символического и информационного, защита доксического характера официального дискурса, отправления и воспроизводства власти - все это формализуется и произносится в юридическом дискурсе об экстремизме. Итак, инструментарий методологического подхода П. Бурдье, объединенный с функционалом препарирования дискурса М. Фуко, обнаруживает весомый потенциал в области дерутинизации смыслов дискурса об экстремизме.

\section{Ссылки:}

1. Бурдье П. О государстве: Курс лекций в Коллеж де Франс (1989-1992 гг.) / ред.-сост. П. Шампань, Р. Ленуар, Ф. Пупо, М.-К. Ривьер ; пер. с фр. Д. Кралечкина, П. Кушнаревой ; предисл. А. Бикбова. М., 2016. 720 с.

2. Там же. С. 114

3. Там же. С. 365

4. Бурдье П. Социальное пространство: поля и практики : пер. с фрр. / сост., общ. ред. Н.А. Шматко. СПб. ; М., 2005. 576 с.

5. Зиновьев А.О. Роль дискурса в организации политических позиций // Журнал социологии и социальной антропологии. 2003. Т. 6, № 4. С. 130-145.

6. Фуко М. Беседа с Ф. Эвальдом // Воля к истине. М., 1996.

7. Зиновьев А.О. Указ. соч. С. 137.

8. О противодействии экстремистской деятельности [Электронный ресурс] : федер. закон от 25 июля 2002 г. № $114-$ Ф3. Доступ из справ.-правовой системы «Гарант».

9. Бурдье П. О государстве ... С. 601.

10. Там же. С. 493.

11. Спиноза Б. Политический трактат. Избранные произведения. М., 1957. Т. 2.

12. Бурдье П. О государстве ... С. 550

13. Там же. С. 50.

14. Там же. С. 662.

15. Там же. С. 62.

16. Там же.

17. Там же. С. 678

18. Там же. С. 335 .

19. Там же. С. 566.

20. Mosse G.L. The Crisis of German Ideology. Intellectual Origins of The Third Reich. N. Y., 1964.

21. Бурдье П. О государстве ... С. 123.

\section{References:}

Bourdieu, P, Champagne, P, Lenoir, R, Poupeau, F, Riviere, M-Ch, Bikbov, A (comps.), Kralechkin, D \& Kushnareva, P (transl.) 2016, On the state lectures at the College de France (1989-1992), Moscow, 720 p., (in Russian).

Bourdieu, P \& Shmatko, NA (ed.) 2005, Social space: fields and practices, St. Petersburg, Moscow, 576 p., (in Russian)

Foucault, M 1996, 'A conversation with F. Ewald', Volya $k$ istine, Moscow, (in Russian)

Mosse, GL 1964, The Crisis of German Ideology. Intellectual Origins of The Third Reich, New York.

Spinoza, B 1957, Political treatise. Selected works, Moscow, vol. 2, (in Russian).

Zinoviev, AO 2003, 'The role of discourse in the political view development', Zhurnal sotsiologii i sotsial'noy antropologii, vol. 6 , no. 4, pp. 130-145, (in Russian). 